dissipate the "hard-won technology capability" already developed in the United States. The dissenters were ERAB chairman Louis Roddis, William S. Lee, president of Duke Power Company, Roland W. Schmitt, vice-president for corporate research at General Electric and John W. Simpson, a consultant previously with Westinghouse Electric. Described by critics as the "electric mafia" on ERAB, these same four are said to have been successful in toning down parts of the report which criticized the emphasis being given by the Reagan Administration to nuclear research as disproportionate to nuclear's role as an energy source.

The final report states merely that "although no correct balance among energy forms and resources can be defined a priori, research and development for electric supply technology is receiving a larger proportion of funding than the present and projected share of electricity in our national energy supplies". In addition to recommending that the Clinch River fast reactor should not be built, the panel suggests that high priority be given to research into nuclear waste disposal and into conventional light-water reactors, and a "little less" funding into both breeder reactor fuel cycle research and magnetic fusion.

David Dickson

\section{Data falsification \\ Harvard acts}

\section{Washington}

Harvard Medical School announced last week that it was setting up a special committee of both faculty members and outside academics to recommend how the school should deal with future cases in which research workers are accused of producing falsified research data.

This announcement follows the resignation of a member of the medical school research staff, Dr John R. Darsee, who admitted that he had fabricated research data during an experiment last year which involved efforts to limit the damage caused by heart attacks in animals.

Dr Darsee also resigned his post as a research fellow at the Brigham and Women's Hospital in Boston. Before his resignation, according to reported comments from other members of the hospital staff, he had been under consideration to head a hospital laboratory.

As a result of allegations about $\mathrm{Dr}$ Darsee's work made last year by other research workers at the medical school, an investigation was carried out, in the course of which Dr Darsee admitted that he had falsified the research results in question.

A statement issued by the dean of the medical school, Dr Daniel C. Tosteson, last week stated that "none of the work which could not be verified has been presented to the scientific community". Earlier this year, Dr Darsee's supervisor, Dr Eugene Braunwald, decided that all

\title{
Christmas present for Heidelberg laboratory
}

The European Molecular Biology Laboratory at Heidelberg has half the Christmas present it was promised a few months ago: a liquid-helium temperature transmission electron microscope lens from Siemens AG, Munich, but not the pictures that should follow from it.

Dr Arthur Jones, head of the electron microscopy group at the laboratory, had hoped the system would have been operational by Christmas. But the lens - only the second commercial such lens in existence (the other went to Berlin) arrived only a week ago. The first pictures, probably of hydrated crystalline specimens at $4 \mathrm{~K}$, are likely to follow in January. Biological specimens should be in view in the spring.

Excitement is intense in the group about what they see as the most important development in electron microscopy for more than a decade. The Siemens group, headed by Dr I. Dietrich, appears to have shown that specimen damage by the electron beam - which limits the available resolution of a microscope on sensitive, nonperiodic biological specimens - may be reduced by orders of magnitude at $4 \mathrm{~K}$.
And at the same time, Dr Jacques Dubochet, in charge of specimen preparation, claims now to produce hydrated biological specimens containing vitrified - non-crystalline - ice. (The formation of crystals would create artefacts and interfere with the imaging of specimens.)

At first, however, the resolution may be no better - or even worse - than with conventional electron microscopy, because the contrast available in hydrated specimens is much less than that possible with negative staining. The reduced beam damage, however, should compensate for this by allowing greater illumination, with the result that the microscope might reveal structures without the artefacts of the conventional stains. Ultimately the use of samples labelled with heavy atoms could make a greater, artefact-free resolution available says Dubochet.

After this "cryo-TEM" will come the scanning version, the "cryo-STEM". The first electron beam down the cryoSTEM is expected by mid-year, with the first images shortly after.

Robert Walgate abstracts of Dr Darsee's work should be withheld from presentation at the annual meeting of the American Heart Association.

The National Institutes of Health (NIH) were also notified of the alleged falsification of data, since Dr Darsee was working on NIH-sponsored research and was in receipt of an NIH research fellowship, which he has since resigned together with his academic posts.

The advisory panel set up by Dean Tosteson is being chaired by Dr Richard Ross, dean of Johns Hopkins School of Medicine. According to last week's statement, the panel has been asked "to review the case in question, and to indicate whether or not any additional measures should be undertaken, and to recommend procedures for dealing with episodes of this kind in the future"'.

The committee has already started work, and its report is expected early in 1982.

\section{David Dickson}

\section{Molecular biology \\ Limited progress}

When the director-designate of the European Molecular Biology Laboratory (EMBL) in Heidelberg takes over from Sir John Kendrew in April, he will not find much room for movement in the budget. Last June, Sir John asked the ten-nation council for DM 32 million ( $£ 7.5$ million) for 1982. In the event the council has now agreed to spend DM 30.2 million, roughly a 10 per cent increase on 1981 compared with a German inflation rate of about 6 per cent.
That allows for a small increase in staff this year - some 20-25 of whom 8-10 will be scientists, according to finance director Eckhart Weis. Thus the laboratory will edge ahead of local inflation, but will come nowhere near the "indicative scheme" prepared in 1980 which foresaw a budget increase of 20 per cent and a staff of 265 rather than the 220 now employed. The directorate, for "scientific reasons", did not fill the 265 posts which were available in 1980 , and since then the recession has meant that the council would not agree to the budget which would be required to reoffer them.

Meanwhile, the new EMBL director, Professor Lennard Philipson of the University of Uppsala, refuses to define his policy for the laboratory until after he is in post. But he has been taking regular soundings, and, it seems, gaining everyone's confidence. He is said to recognize the important and unusual role that physicists play at the laboratory and the significance of the EMBL outstations at DESY, Hamburg (a synchrotron radiation source which has a long queue of applicants for beam time) and the Institut Laue Langevin, Grenoble (a neutron source).

It seems likely that the new regime will see a greater integration of the work at Heidelberg, and between Heidelberg and the outstations, with the selection of two or three principal areas of biology (cell membranes, for example) as broad foci of interest. But there will be nothing so blockbusting as an attack on the whole human chromosome - "that's factory work" said one senior EMBL scientist. On the 
instrumentation side, certain techniques, such as gel electrophoresis, which are central to the new methods of molecular biology, may be singled out for increased attention; but Philipson is also said to have shown his support for the great efforts being made at Heidelberg to improve electron microscopy through cooling the microscope and specimen (see accompanying box).

At present Sir John Kendrew is still firmly in charge. He foresees an increase in the number of permanent scientific appointments (still less than a handful) at the laboratory in the next couple of years, as a batch of the early short-term contracts come to an end. Philipson, however, has made no commitments. As for Sir John himself, he feels that the seven years and three months for which he will have held the directorship is quite long enough.

Robert Walgate

\section{Polish crisis}

\section{Science in limbo}

The "state of war" proclaimed by General Jaruzelski's "Military Council for National Salvation" has brought all academic life in Poland to a standstill. The universities are closed as are several institutes of the academy of sciences. Scores of scientists and scholars have been arrested although some, such as the president of the academy, Dr Aleksander Gieyszter, have since been released. Others escaped arrest only by chance, being away from home when the police came, and are now in hiding. Solidarity organizers in the learned professions and activists from the Independent Students' Association have been interned. The Minister of Science, Higher Education and Technology, Dr Jerzy Nawrocki, is reported to have resigned.

This clamp-down on intellectuals is in sharp contrast with Jaruzelski's previous attitude. In a recent interview, Dr Leonard Sesnewski, one of the vice-presidents of the academy, said that Jaruzelski had always expressed warm feelings for scientists and that, on taking of fice as prime minister last February, he had immediately visited the academy to ask for their help in getting Poland out of its economic crisis.

Nevertheless, the growing drive for academic autonomy must have caused a certain friction between the general and the academy. At present, the academic secretary of the academy holds quasiministerial rank, and is responsible to the prime minister. In recent months, however, there has been considerable pressure from academy members and employees to incorporate into the proposed new bill on the academy clauses that would terminate this structure and make the academic secretary responsible only to his fellow-academicians. There has also been a drive - reflected in the Solidarity Congress resolution on learning and culture - to break down the barriers between the universities and the academy, so that academy employees could deliver lectures to undergraduates. This trend may have seemed dangerous to the authorities; a number of scholars, expelled or excluded from teaching posts for their political views over the past few years, have found a safe haven in academy research posts insulated from teaching.

For the time being, the concern of scholars abroad is focused on the plight of their Polish colleagues interned or in hiding. Professor Olof Tandberg and his colleagues from the Swedish Academy of Sciences (which traditionally has strong links with Poland) and several members of the Norwegian Academy have launched an appeal for financial support for the families of interned academics. Professor Tandberg has also received an appeal from a group of academy scholars in hiding asking for food, blankets and other essential supplies, including blood plasma. $\mathrm{He}$ has called on all other academies throughout the world to join the Norwegian and Swedish academics in this work.

Vera Rich

\section{UK agricultural research Endangered duo}

Two British agricultural research institutes, the Long Ashton Research Station in Bristol and the Animal Breeding Research Organisation in Edinburgh, could be drastically cut or even closed if an economy proposal by the Agricultural Research Council is approved at its next meeting in February. Under threat are all research programmes at the Edinburgh institute except work on fundamental animal genetics, and the Pomology and Food and Beverages Division at Long Ashton.

The council (ARC) hopes the closures will save about $£ 3$ million in annual expenditure by 1983-84. (The budget for 1981-82 is £86 million.) According to $\mathrm{Dr}$ Ralph Riley, the secretary of ARC, the savings are needed both as a hedge against future government cuts and to allow greater flexibility in supporting research of high priority. The council's research programme has already suffered, he says, from a budget that has not kept up with inflation. Non-payroll expenditure has already been pared to the bone. But precisely how much of the $£ 3$ million saved will be available for starting new research projects after cuts in income are taken into account remains uncertain.

If the proposal is approved, the Long Ashton Research Station will be reduced to about one half of its present strength, with the loss of about 100 jobs. The Animal Breeding Research Organisation, however, will probably be closed and the research on animal genetics, which accounts for about one-fifth of the organization's activity, moved elsewhere.

ARC has made the proposal without consulting the staff or directors of the institutes concerned, who first learnt of it only last week. The idea, according to Dr Riley, was for ARC to propose firm suggestions for savings and then to give those concerned two months in which to make a case before a final decision. The way in which the proposal was arrived at remains something of a mystery, but the main criterion seems to have been an assessment of priorities based on recent reviews of the work of all the council's institutes. Areas in which the council is likely to want to spend more money include fundamental genetics and biotechnology.

If approved, the proposal could have implications for the Ministry of Agriculture, Fisheries and Food, which spends about $£ 44$ million a year in ARC institutes on commissioned research. The ministry is optimistic that the work it commissions in the institutes under threat could be transferred to other institutes. Dr Riley, however, believes that this will be possible for most commissioned research but that there may be some areas where the ministry will have to look elsewhere. Judy Redfearn

\section{High-energy physics \\ LEP marches on}

The large electron-positron ring is on the move - in more than one sense. LEP will be the next big accelerator at CERN, the European Centre for Nuclear Physics, Geneva, and last week CERN member states finally agreed on the budget under which it will be built. Thus construction can begin as soon as local environmental approval is granted - by January or February, it is hoped. The second move is physical: LEP is to be built in a significantly new position, on a slope, which allows it to slide out of some tricky geological and political problems.

The budget agreed is sufficient, says CERN director-general Professor Herwig Schopper, to build LEP on the schedule foreseen a few months ago: fast enough to give colliding electron and positron beams of sufficiently high energy to provide physicists with copious neutral intermediate vector bosons by the end of 1987 .

LEP is expected to cost SF910 million (about $£ 263$ million) at 1981 prices, with a further SF40 million (making a total of $£ 275$ million) for the first experiments. The money will be drawn from a guaranteed CERN annual budget of SF617 million.

The only major argument at the council was over what inflation index to apply to the 1981 budget to scale it up to 1982 prices. The usual CERN formula, appropriately weighted for CERN's Swiss salaries and expenditure abroad, gave 5.7 per cent. The council quibbled, and agreed on 4.4 per cent, losing CERN over $£ 2$ million next year.

The new slope for LEP (it was to have been horizontal) will be about 1.5 per cent from the Jura Mountains in the north west, towards Geneva. This enables the machine 